\title{
Parental Attitudes towards Children with Intellectual Disability in Special Schools of South India.
}

\author{
Safa Puliyakkadi ${ }^{1}$, Nileena Koshy ${ }^{2}$, Sajna Mathumkunnath Vijayan ${ }^{3}$, Binu Areekal ${ }^{4}$, \\ Ashwin Raj ${ }^{5}$, Swathi Chalil ${ }^{6}$ \\ ${ }^{1}$ Senior Resident, \\ ${ }^{2}$ Additional Professor, Department of Community Medicine, Government Medical College, Manjeri, \\ Kerala, India \\ ${ }^{3}$ Associate Professor, \\ ${ }^{4}$ Additional Professor, \\ ${ }^{5}$ Assistant Professor, MES Academy of Medical Sciences, Malappuram, Kerala \\ ${ }^{6}$ Junior Resident \\ 1,3,4,6Department of Community Medicine, Government Medical College Thrissur, Kerala, India . \\ Corresponding author: Safa Puliyakkadi \\ Email: safapuliyakkadi@gmail.com
}

\begin{abstract}
Background: Parental attitude is one of the key prognostic factors in psychosocial development of a child. In this cross-sectional study conducted in the special schools among parents, we explored the dimensions of parental attitudes towards children with intellectual disability and the factors that influence these attitudes. Methodology: Data was collected using Rangaswamy Parental Attitude Scale. This scale consists of 40 items spread equally into 8 domains (over protection, acceptance, rejection, permissiveness, communication, attitudes towards education, home management and hostility).

Results: The study revealed that parents have an overall positive attitude towards their children with intellectual disability. However, mean score of the subscale domains indicates parental negative attitudes which is highest on over protection and lowest on rejection.

Conclusions: Further studies in this regard are needed across multiple centres to validate the findings of the above study.
\end{abstract}

Keywords: Intellectual disability, Parental attitude, Special school, Overprotection, Rejection

(Paper received $-17^{\text {th }}$ March 2021, Peer review completed $-8^{\text {th }}$ May 2021, Accepted $-10^{\text {th }}$ May 2021)

\section{INTRODUCTION}

Birth of a child into a family is a vital event in the parent's life. This event is marked by surge of emotions from the parent's side, and this phase is conspicuous by feelings of hope and happiness. The parents usually carry certain expectations about their child. However, when they are faced with the knowledge that their child is intellectually disabled, they may be confronted with a wide range of emotions. Intellectual disability, for them is a deficiency in the part of the child, unforeseen in their imagination of the perfect child.

The parents of children with disabilities may develop 'chronic sorrow' characterized by periodic recurrence of sadness, guilt, shock and pain [1]. Feelings of pessimism, hostility, and shame, denial, projection of blame, guilt, grief, withdrawal, rejection, and acceptance are some of the usual parental reactions that are reported [2]. Some parents also experience helplessness, feelings of inadequacy, anger, shock and guilt, whereas others go through periods of disbelief, depression, and self-blame [2-3].

Parental attitude is one of the key prognostic factors in psychosocial development of a child. Eagly defines attitude as "a psychological tendency that is expressed by evaluating a particular entity with some degree of favor or disfavor" [4]. In this study, attitudes imply how parents react towards their children with intellectual 
disability on various dimensions such as overprotection, acceptance, rejection, permissiveness, dominance, education and future, hostility and home management [5]. The cultural variations and perceptions of the society in addition to economic and psychological stressors are seen to affect the attitude of the parents. Limited financial resources, lack of appropriate services, and insufficient support systems are the family system risk factors that can contribute to poor prognosis [6].

India being a country with cultural and social diversity with limited studies on this topic, it becomes important to explore the dimensions of parental attitudes of children with intellectual disability in the setting.

\section{METHODOLOGY}

\section{Participants}

The Cross-sectional study was conducted in Kerala state of India. Parents of children with intellectual disability, aged 0-12 years, enrolled in special schools were included in the study. Thrissur district has got 17 special schools for intellectually disabled children. Each school was considered as one cluster. It was decided to include two clusters in this study. Total number of students in each school was obtained. It was decided to include equal participants from each cluster. From the attendance register of the schools (study clusters), a sampling frame was prepared for the respective schools. From the list, required participants $(n=100)$ were selected from the two schools by simple random sampling. After selecting the students, the contact details of the parents were obtained from the school authorities. The parents were contacted and a meeting was arranged at the school.

\section{Instrument}

After ensuring sufficient privacy, the parents were interviewed, by the same investigator with the semi structured interview schedule. The interview schedule consisted of information regarding sociodemographic details, and profile of the child. The parental attitude was measured with the Rangaswamy parental attitude scale. The Rangaswamy questionnaire was given to the parents for self-administration. In the questionnaire, the parental attitude is explained across eight domains, the maximum score across each domain being 10 , thus the maximum total score being 80 . This scale consists of 40 items spread equally into 8 areas. Over protection, acceptance, rejection, permissiveness, communication, attitudes towards education, home management and hostility. Three-point scale pattern was adopted. The items are to be answered in terms of 'yes', 'cannot say', and 'no'. Items from 1-5, 9-15, 21-27, 31-40 were scored using the pattern of No-0; cannot say-1; and yes-2. Item numbers from 6-8, 16-20, and 28-30 are scored with scoring patterns of yes-0; cannot say-1; and no-2. Thus, maximum possible score is 80 . Higher the score, the stronger the negative attitude. The sub-scales are arranged in such a way that first five items are about over protection, and the following every five consecutive items are about acceptance, rejection, permissiveness, communication, attitudes towards education, home management and hostility respectively.

\section{Operational Definition of Variables}

Overprotection: Undue or excessive protection or shielding specifically; excessive restriction of a child's behavior allegedly in the interest of his or her health and welfare by an anxious, insecure, or domineering parent.

Acceptance: It refers to the affection, warmth and love of parents towards their child, and accepting the child as an individual, in spite of the presence of the intellectual disability.

Rejection: Withholding of affection from or denial of attention to one's child; particularly because the child is intellectual disabled.

Permissiveness: It is the degree which a parent allows their intellectually disabled child freedom to make their own choices and take responsibility for their own actions.

Dominance: The degree to which a parent holds a control over the activities and choices of the intellectually disabled child.

Education and future: The optimistic or pessimistic attitude that a parent shows towards the education and future of the child. 
Home management: The parental perception of the capability of the child in effectively running a household.

Hostility: It is an internal feeling of anger, resentment or malice of parents towards the child particularly because the child is intellectually disabled.

\section{Data Analysis}

Parental attitude score was expressed by mean and standard deviation with $95 \%$ confidence interval. Association of parental attitude score with socio-demographic variables was done using $t$ test and Chi square test. A two-tailed $\mathrm{P}<0.05$ was considered statistically significant.

\section{RESULTS AND DISCUSSION}

\section{Sociodemographic details of the study participants}

The mean age of the study participants was $37.72 \pm 6.60$ years. While $63 \%$ (63) of the study participants were mothers, $37 \%$ (37) were fathers. In the study, 29(29\%) of study participants were from urban area while $71(71 \%)$ were from rural area. Highest number of study participants were Christians $49(49 \%)$, followed by Hindus $42(42 \%)$ and Muslims $9(9 \%)$. More than half of the study participants, $62(62 \%)$ belonged to the nuclear family, while $22 \%$ (22) were from three generation family, and $16 \%$ (16) from joint family. Majority of mothers were unemployed $79(79 \%)$, while majority of fathers were engaged in unskilled work $28(28 \%)$, followed by semiskilled work $23(23 \%)$.

\section{Profile of the children}

$24(24 \%)$ of the children were females, while $76(76 \%)$ were males. The median age at which disability was recognized was 5 months. The age of recognition of disability ranged from birth to 10 years. 7 (7\%) of the children were the only child, while 32 (32\%) were first child and $45(45 \%)$ were second child.

\section{Parental Attitude}

Table 1: Parental attitude score

\begin{tabular}{|c|c|c|}
\hline Mean & SD & $\mathbf{9 5 \%}$ CI \\
\hline 34.04 & 8.77 & $32.06,35.85$ \\
\hline
\end{tabular}

As per Table 1, the total parental attitude score of the study participants was $34.04 \pm 8.77$. The score ranged from 16 to59.

Table 2: Parental attitude score across eight domains

\begin{tabular}{|c|c|c|c|c|c|c|c|c|}
\hline Domain & OP & AC & RE & PE & DO & ED & HM & HO \\
\hline Mean score & 7.03 & 3.28 & 1.73 & 5.34 & 3.83 & 6.29 & 4.01 & 2.53 \\
\hline SD & 2.20 & 2.26 & 1.90 & 2.51 & 2.56 & 3.04 & 1.85 & 2.33 \\
\hline
\end{tabular}

$(O P=$ Over protection, $A C=$ Acceptance, $R E=$ Rejection, $P E=$ Permissiveness, $D O=$ Dominance, $E D=E d u c a t i o n$ and future, $H M=$ Hostility, $H O=$ Home management and $T A=$ Total attitudes).

Figure 1: Range of parental attitude across the eight domains

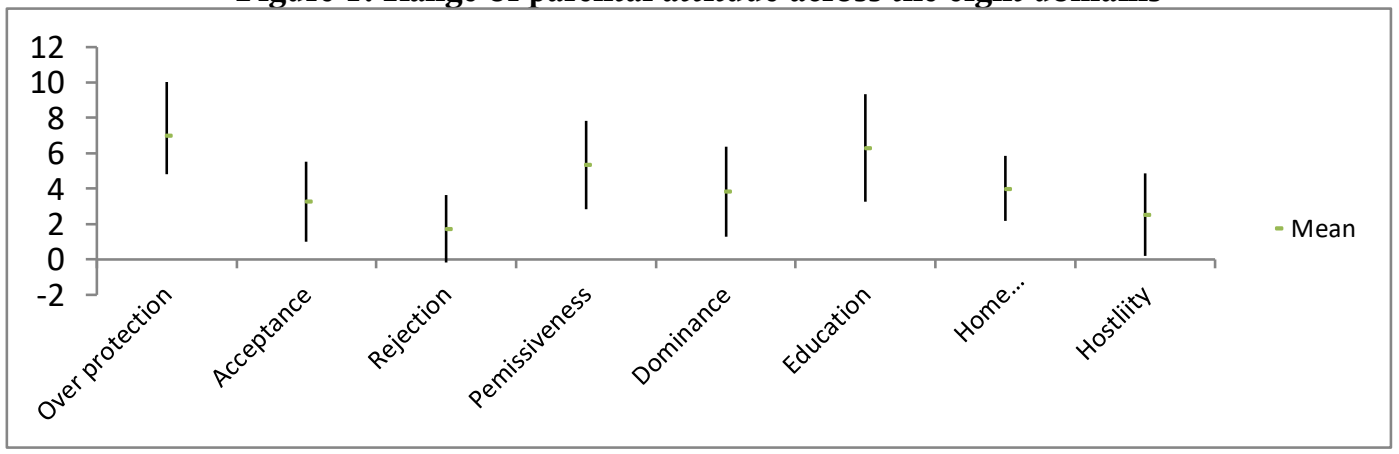


Table 3: Association of socio-demographic factors with total parental attitude

\begin{tabular}{|l|l|l|l|l|l|l|l|}
\hline Socio-demographic factor & N & Mean & SD & df & t value & p value \\
\hline \multirow{2}{*}{ Respondent } & Father & 37 & 33.27 & 9.21 & 98 & 0.67 & 0.50 \\
\cline { 2 - 5 } & Mother & 63 & 34.49 & 8.54 & & & \\
\hline \multirow{2}{*}{ Residence } & Rural & 71 & 35.23 & 8.54 & 98 & 2.17 & $0.032^{*}$ \\
\cline { 2 - 5 } & Urban & 29 & 31.10 & 8.78 & & & \\
\hline \multirow{2}{*}{ parents } & $<30$ years & 9 & 36.11 & 8.00 & 2 & 0.29 & 0.74 \\
\cline { 2 - 5 } & $\mathbf{3 0 - 4 0}$ years & 64 & 33.70 & 8.19 & & & \\
\cline { 2 - 5 } & $\mathbf{> 4 0 y e a r s}$ & 27 & 34.04 & 10.22 & & & \\
\hline
\end{tabular}

Table 4: Association between total parental attitude and profile of the child

\begin{tabular}{|c|c|c|c|c|c|c|c|c|}
\hline \multicolumn{2}{|c|}{ Profile of child } & N & Mean & SD & $\begin{array}{c}\text { Mean } \\
\text { difference }\end{array}$ & df & t value & p value \\
\hline \multirow{2}{*}{ Gender } & Male & 76 & 33.64 & 8.60 & -1.64 & 98 & -0.80 & 0.42 \\
\cline { 2 - 8 } & Female & 24 & 35.29 & 9.36 & & & & \\
\hline \multirow{2}{*}{$\begin{array}{c}\text { Presence of } \\
\text { other } \\
\text { disability }\end{array}$} & Present & 48 & 34.29 & 8.82 & -0.48 & 98 & 0.27 & 0.78 \\
\cline { 2 - 6 } & Absent & 52 & 33.80 & 8.80 & & & & \\
\hline $\begin{array}{c}\text { Number of } \\
\text { children }\end{array}$ & Only child & 7 & 35.57 & 8.79 & 1.64 & 98 & 0.47 & 0.63 \\
\cline { 2 - 8 } & Siblings & 93 & 33.92 & 8.80 & & & & \\
\hline
\end{tabular}

\section{DISCUSSION}

The total parental attitude score of the study participants is $34.04 \pm 8.77 .95 \% \mathrm{CI}(32.06,35.85)$. The score in the study ranges from 16 to59. Lower the score more the positive attitude towards the child. In the present study, it was found that parent have an overall positive attitude towards children with intellectual disability. This study reports a better attitude when comparing with other studies which was conducted in National Institute of Mental Health and Neurosciences, Banglore (36.13 \pm 7.38$)$ [3], and among non-governmental organizations in North India(46.29 \pm 6.10$)$ [4].

Majority of the parents, that is, $73(73 \%)$ had positive attitude, (score below 40 ), while $27(27 \%)$ of parents had negative attitude (score above 40).This is comparable to other studies like the study conducted in Guwahati, Assam by Mythili Hazarika which reports that $88 \%$ of parents accepted and loved their children [7]. In another study conducted by Dr.Sribas Goswamy, it was observed that 27 out of 30 parents have shown their favourable parental attitude which is above $50 \%$ of the total score set of the study [8]. But in a study by V. Ravindranadan and Raju, S. mentioned that some parents may still feel ashamed of their wards with disabilities and consider them as a burden [9].

The lowest mean score is in the domain of rejection and the highest mean score is in the domain of over protection which implies that parents had a tendency to over protect the child, while they did not reject the child because of the presence of intellectual disability.

Overprotection was assessed with questions inquiring whether 1) The parent feels it is better to keep the child under parents constant supervision 2) If the parent care for this child more than other children 3) Whether the parent thinks their presence can avoid the child's misbehavior 4) If they often consult others (including experts) on how to handle the child and 5) If they help or assist the child even for simple things.

Majority of the parents gave 'yes' as an answer to these questions which implies that there is a tendency to overprotect the child. Similar findings, was reported in a study conducted by Nirmal Thengal and Mythili Hazarika [7]. Being overprotective is an unfavorable attitude when we take in to account the psychosocial development of the children. Some degree of self-reliance must be nurtured in the children, so that they can 
attain the maximum possible development, in accordance with the degree of their disability. This can enhance betterment in their psychological and social spheres and boost their self-confidence.

Rejection was assessed using the questions 1) If the parents felt ashamed of this child's behavior in Public Places 2) If they favor other children and show more affection to them than to this child 3) If they have disliked the child at any time 4) If they wished to get rid of the child 5) If they felt greatly relieved when the child was away. Majority of the parents gave 'no' as an answer to this question, which implies that parents did not reject the child in spite of them being intellectually disabled. Contrary to the finding in the present study, the study done among non-governmental organizations in North India showed a high score (7.66 \pm 1.66$)$ in the domain of rejection [4]. This difference in attitude can be due to the differential literacy rates, particularly female literacy rates that exist across North Indian and South India states.

In the present study, there was no significant difference in attitude between mothers and fathers (Table 3). Similar finding were obtained in the study by Thengal in Assam, which used a five point likert scale by reviewing multiple scales to assess attitude

There was a statistically significant association between the residence and total parental attitude. Parents hailing from urban area had more positive attitude as compared to parents from rural area ( $p$ value $=0.032$ ) (Table 3). This rural-urban difference in attitude was also observed in a study conducted by Vidhya Ravindranadan [9]. One possible reason could be that urban residents are more likely to acquire the rehabilitation measures and resources and they might have more awareness on the condition, since they have better accessibility to the services for these children.

When the associations between profile of the child and total parental attitude was explored (table :4), it was found that there was no significant difference in attitude of parents based on the gender of the child, number of children or presence of disability in the child other than intellectual disability. But few studies did obtain clear differences in parental perceptions related to the profile of the children. The study done by Chandramukhi which used Rangasway Parental Attitude questionnaire, revealed a higher score towards boys (36.53) as compared to girls (29.93) [3]. Another study, conducted in Nigerian also did reveal significant differences related to gender of the children on various sub domains of the scale.

\section{CONCLUSION}

Mean score of subscale domains indicates parental negative attitude which is highest on over protection and lowest on rejection, which indicates that there is tendency of parents to overprotect the child but not reject their child due to presence of intellectual disability. In the present study, there was no significant difference in attitude between mothers and fathers. that there was no significant difference in attitude of parents based on the gender of the child, number of children or presence of disability in the child other than intellectual disability. When the socio-demographic factors are looked into, it was seen that, parents hailing from rural area has more negative attitude as compared to parents from urban area.

Compliance with Ethical Standards: All procedures performed in studies involving human participants were in accordance with the ethical standards of the institutional research committee and with the 1964 Helsinki Declaration and its later amendments or comparable ethical

\section{REFERENCES}

1. Wikler L, Wasow M, Hatfield E. Chronic sorrow revisited: parent vs. professional depiction of the adjustment of parents of mentally retarded children. Am J Orthopsychiatry 1981;51(1):63-70.

2. Drew CJ, Logan DR HM. Mental Retardation - A Lifecycle Approach. Toronto Times Mirror/ Most Coll Publishers; 1984.

3. Chandramuki D, Venkatakrishnashastry I, Vranda MN. Attitudes of Parents towards Children with Specific Learning Disabilities. Disabil CBR Incl Dev [Internet] 2012;23(1):63-9.

4. Shamim M, Osman AA. Parental attitudes towards children with mental retardation: Across sectional study from NGOs in Northern India. Int J Res Health Sci 2015;3(2):267-73.

5. Rangaswamy K. Construction of a Scale to Measure Parental Attitude Towards Problem Children. Child Psychiatry Q 1989;22(2/3):75-80. 
6. Mash EJ, Barkley RA. Treatment of childhood disorders [Internet]. Guilford Press; 2006.

7. Hazarika M, Das S, Choudhury S. Parents 'Attitudes Towards Children and Adolescents With. Int J child Dev Ment Heal 2017;5(1):11-21.

8. Goswami S. The Parental Attitude of Mentally Retarded Children. Glob J Hum Soc Sci Arts Humanit. 2013;13(6).

9. Ravindranadan V, Raju S. Adjustment and attitude of parents of children with mental retardation. J Indian Acad Appl 2007;33(1):137-41.

10. Thengal, N. Attitude of parents and family members towards their mentally retarded children in Assam. Int J Behav Soc Mov Sci 2013;2(1):196-210.

Acknowledgements - Nil.

Conflict of Interest - Nil.

Funding - Nil. 